\title{
Experimental Investigation into Multistage versus Conventional Triaxial Compression Tests for a c-phi Soil
}

\author{
Mohamed A. Shahin ${ }^{1, a}$ and Alice Cargeeg ${ }^{2, b}$ \\ ${ }^{1}$ Senior Lecturer, Curtin University, Department of Civil Engineering, Perth, WA, Australia \\ ${ }^{2}$ Graduate Engineer, Main Roads Western Australia, Perth, WA, Australia \\ am.shahin@curtin.edu.au, balice.cargeeg@mainroads.wa.gov.au
}

Keywords: c-phi soil, laboratory experiments, multistage, triaxial compression.

\begin{abstract}
The procedure for conventional triaxial compression (CTC) test requires three separate soil specimens to be examined to failure under different confining pressures so that Mohr-Coulomb (or stress path) failure envelope can be determined and soil shear strength parameters can be obtained. An alternative procedure is the multi-stage triaxial (MST) compression test, which requires only one soil specimen to be tested at three stages of shearing with different confining pressures. There are several advantages for using MST over CTC, which apart from fewer soil specimens, include less laboratory time consumption and reduced effects of heterogeneity among the specimens tested. However, it has been argued in the literature that the advantages of using MST may be compromised by its inability to obtain reliable soil behavior or accurate shear strength parameters. In this paper, the accuracy of MST compared to CTC is investigated for a $c$-phi soil, and a simple procedure that can be adopted to rectify the MST results is proposed.
\end{abstract}

\section{Introduction}

The multi-stage triaxial (MST) compression test was first introduced by De Beer [1] as a possible alternative method for determining the shear strength parameters of soils by means of testing a single soil specimen instead of the usual three soil specimens used in conventional triaxial compression (CTC) tests. Kenney and Watson [2] were among the first researchers who successfully applied the multi-stage principle to measure the effective soil cohesion, $c^{\prime}$, and friction angle, $\phi^{\prime}$, for fully saturated soils. The multistage procedure uses one soil specimen that is consolidated under different confining (cell) pressures and then axially loaded at each confining pressure until a failure axial strain is reached. The detailed procedure of performing a MST test include consolidating the soil specimen with the first confining pressure, and then steadily apply axial load until the soil specimen deforms plastically. The confining pressure is then increased and the axial load is resumed until the soil specimen fails a second time. The above procedure is repeated for a third time under increased confining pressure and the results are used to draw the Mohr-Coulomb failure envelope, from which the soil cohesion and friction angle are obtained.

Whilst the above procedure may give reasonable shear strength parameters for some soils, it has a serious limitation that the tested soil specimen undergoes a large amount of axial strain towards the end of the last stage [3]. To overcome this problem, Sridharan and Rao [3] suggested that at each stage of the multi-stage procedure, the axial load needs not to be conducted to failure but to 'near failure' point (identified to be $2-4 \%$ of the axial strain) and then the limits of Kondner's [4] hyperbolic relationships between the confining pressure and rate of strain are used to predict the point of asymptotic failure strain and associated deviator stress. Sridharan and Rao [3] observed that the results obtained from the predicted deviator stresses at failure derived from the asymptotic failure strain are usually higher than those obtained experimentally using the CTC tests. They acknowledged that their proposed method is valid only for those soils which demonstrate a linear relationship when transformed using Kondner's hypothesis. 
Nambiar et al. [5] identified that to obtain accurate shear strength parameters, there is a need to evaluate the effects of limiting strain experienced by the soil specimen. They suggested a specific procedure to obtain a finite failure strain (as alternative to the infinite asymptotic failure strain) by which the deviator stresses obtained from the MST can be predicted at failure using Kondner's [4] hyperbolic relationships. As suggested by Nambiar et al. [5], the finite failure strain requires conducting a CTC test on an individual soil sample at consolidation pressure equal to the in-situ overburden pressure. It was found by Nambiar et al. [5] that the predicted failure deviator stresses at the finite failure strain give comparable shear strength parameters to those obtained from the CTC control procedure. However, the drawback associated with this procedure is the requirement for an additional CTC test. In this paper, a modification to this procedure is proposed in which the finite failure strain is obtained in a parsimonious manner that negates the need for an additional CTC test. The modified procedure has been found to give good results in obtaining the shear strength parameters for a $c$-phi soil.

\section{Kondner's Hyperbolic Relationships for Determining Shear Strength Parameters}

As mentioned earlier, in order to avoid subjecting the soil specimens to high strain during multi-stage triaxial (MST) compression test, Sridharan and Rao [3] made use of Kondner's [4] hyperbolic relationships for predicting the state of stress at failure from the stress-strain data observed at low strains. Instead of loading the sample till failure for each stage of consolidation pressure in MST, loading can be stopped at low strain equal to $2-4 \%$, and Kondner's [4] hyperbolic stress-strain relationships can then be used to predict the deviator stresses at failure. Kondner's [4] demonstrated that the stress-strain curves of soils can be approximated by rectangular hyperbolae that can be mathematically expressed as follows:

$$
\frac{\varepsilon_{a}}{\sigma_{1}-\sigma_{3}}=a+b \varepsilon_{a}
$$

where; $\varepsilon_{a}$ is the axial strain, $\left(\sigma_{1}-\sigma_{3}\right)$ is the deviator stress, and $a \& b$ are empirical constants that can be obtained experimentally from Kondner's linearization. A plot of $\varepsilon_{a} /\left(\sigma_{1}-\sigma_{3}\right)$ versus $\varepsilon_{a}$ is a straight line in which its slope gives the value of $b$, and its intercept with the the axis of $\varepsilon_{a} /\left(\sigma_{1}-\sigma_{3}\right)$ gives the value of $a$. The value of deviator stress at failure $\left(\sigma_{1}-\sigma_{3}\right)_{f}$ can then be obtained by taking the limit of Eqn. (1) for $\varepsilon_{a} \rightarrow \infty$, as follows:

$$
\left(\sigma_{1}-\sigma_{3}\right)_{f}=\lim _{\varepsilon_{a} \rightarrow \infty}\left(\sigma_{1}-\sigma_{3}\right)=\frac{1}{b}
$$

Thus, it is possible to obtain the failure stresses from the MST by determining $b$ using the stress-strain data at low strains of $2-4 \%$.

It should be noted that Sridharan and Rao [3] have found that the predicted asymptotic values of $\left(\sigma_{1}-\sigma_{3}\right)_{f}$ using Kondner's [4] hyperbolic equations are generally higher than those obtained from the CTC tests. Consequently, they suggested that when extrapolating data using Kondner's equations, better predictions may be obtained if the extrapolation is carried out to a finite value of strain rather than to the infinite asymptotic value, and they proposed a tentative finite strain value of $15 \%$. However, for MST carried out on sedimented kaolinitic clay, Nambiar et al. [5] found that a finite strain value of $10 \%$ gives better predictions. Nambiar et al. [5] also proposed a rational procedure for determining the magnitude of the finite failure strain and the shear strength parameters, as follows:

1. Conduct a CTC test on an individual soil sample at consolidation pressure equal to the in-situ overburden pressure;

2. Use the results obtained from the above test and plot $\varepsilon_{a} /\left(\sigma_{1}-\sigma_{3}\right)$ versus $\varepsilon_{a}$, and determine Kondner's experimental constants $a \& b$; 
3. Use Eqn. (1) to predict $\left(\sigma_{1}-\sigma_{3}\right)_{f}$ at different assumed failure strains, slightly higher and lower than the observed failure strain, and determine the strain at which extrapolation yields the best agreement with the CTC test (i.e. the finite failure strain);

4. Conduct the MST test on another soil sample and at each stage of the multi-stage loading, stop the test at a value of an axial strain between $2-4 \%$;

5. For each stage of the MST, use Eqn. (1) to predict $\left(\sigma_{1}-\sigma_{3}\right)_{f}$ at the finite failure strain obtained in Step 3; and

6. Use the deviator stresses predicted in Step 5 to draw the Mohr-Coulomb failure envelope from which the shear strength parameters can be determined.

Nambiar et al. [5] demonstrated that the above procedure has resulted in a good agreement between the MST and CTC tests for obtaining the shear strength parameters of a sedimented kaolinitic clay. The above procedure, however, has the disadvantage of requiring an additional CTC test to be conducted on an individual soil sample to obtain the finite failure strain. A modification to this procedure is proposed in the current study in which an additional CTC test is not needed. The modified procedure is applied to a $c$-phi soil, and the results are presented and discussed.

\section{Testing Program and Results}

\section{Material Tested}

The soil used in this study is obtained from a local quarry in Perth, Western Australia, and classified by the Unified Soil Classification System (USCS) as poorly graded sand with high plasticity silt (SP-SM). The soil has specific gravity of 2.6 , liquid limit of $51 \%$, plastic limit of $31 \%$, maximum dry unit weight of $17.1 \mathrm{kN} / \mathrm{m}^{3}$ and optimum moisture content of $16.5 \%$.

\section{Conventional Triaxial Compression Testing}

Three conventional consolidated undrained triaxial compression (CUTC) tests are carried out on soil samples of a diameter $=38 \mathrm{~mm}$ and height $=80 \mathrm{~mm}$. Before conducting the CUTC tests, each soil sample is brought to the optimum moisture content and compacted in five layers to about $95 \%$ of the maximum dry unit weight. The CUTC tests are conducted at three different confining pressures of 50, 100 and $200 \mathrm{kPa}$, and the tests are stopped when an axial strain of $25 \%$ is achieved. The results of the stress-strain curves are shown in Fig. 1. These results are used to plot the Mohr-Coulomb failure envelope shown in Fig. 2, from which the effective shear strength parameters are determined to be as follows: cohesion, $c^{\prime}=23 \mathrm{kPa}$ and friction angle, $\phi^{\prime}=29^{\circ}$.

\section{Multi-Stage Triaxial Testing}

The multi-stage triaxial (MST) compression test is conducted on a single soil sample at three stages of confining pressures equal to 50,100 and $200 \mathrm{kPa}$. As recommended by Nambiar et al. [5], the soil sample is loaded till an axial strain of $3 \%$ before the subsequent stage commences, and the data obtained are used to obtain Kondner's hyperbolic constants. However, instead of conducting a CTC on an individual soil sample to obtain the finite failure strain at which the deviator stresses can be predicted, the third stage of the multi-stage loading is continued to an axial strain of $25 \%$ and the data obtained from this stage are used to obtain the finite failure strain. The results of the stress-strain obtained from the MST tests are shown in Fig. 3, and the linearization of the data obtained from the third stage is depicted in Fig. 4. It can be seen from Fig. 3 that the ceasing shearing in stages one and two do not extend to actual failure, and it is for this reason that Kondner's hyperbolic relationships are used to predict the failure values of deviator stresses to enable the calculation of the shear strength parameters. 


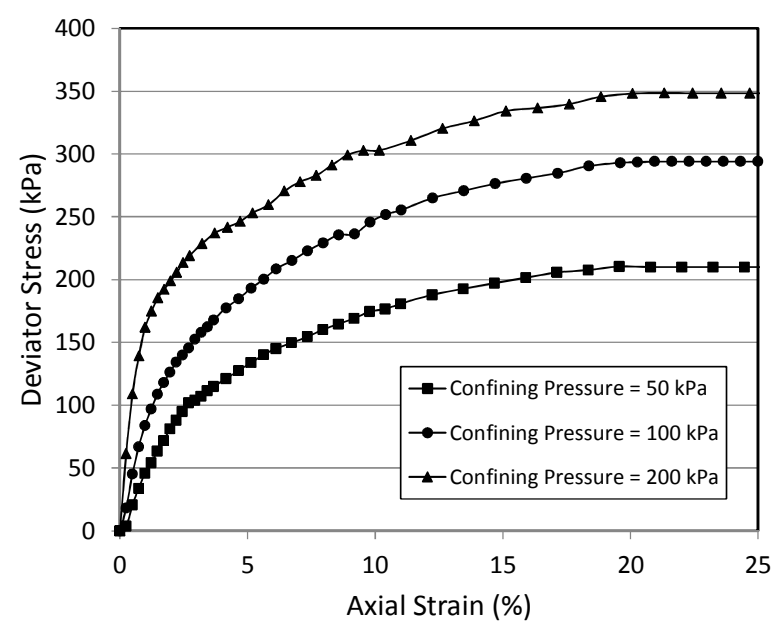

Fig. 1: Stress-strain curves of the CUTC tests

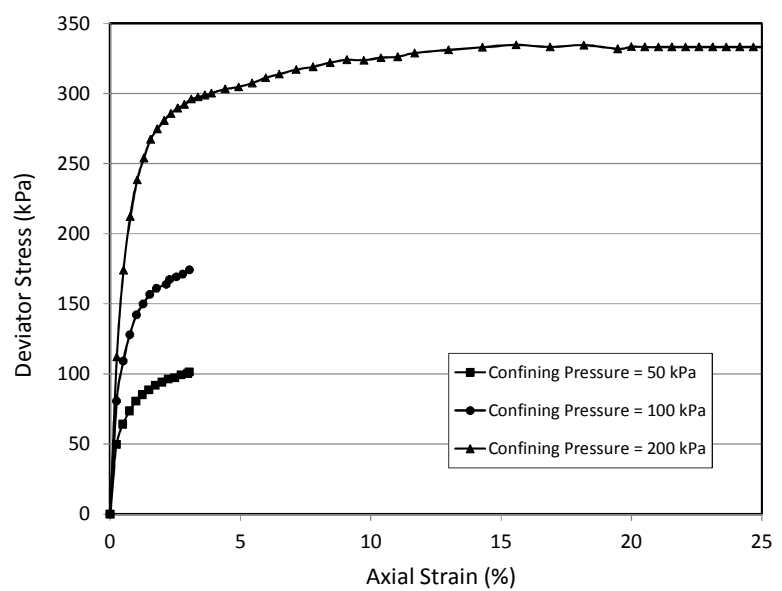

Fig. 3: Stress-strain curves of the MST test

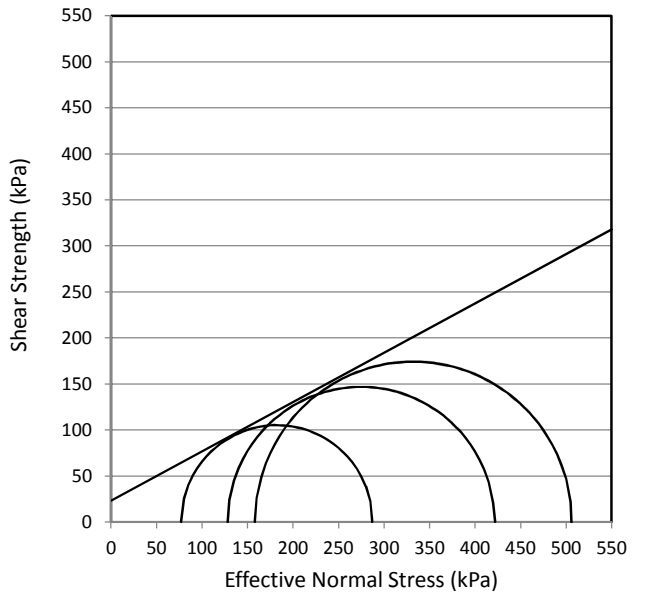

Fig. 2: Mohr-Coulomb failure envelope of the CUTC test

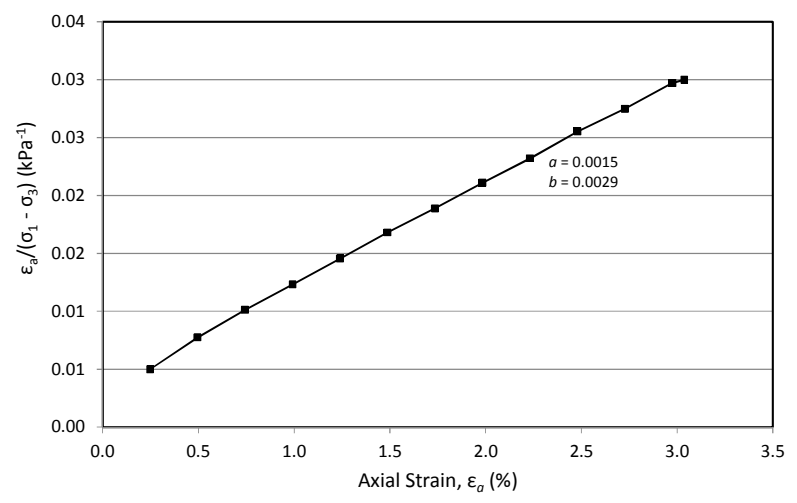

Fig. 4: Hyperbolic linearization of the MST third stage of loading

Table (1) shows the values of $\left(\sigma_{1}-\sigma_{3}\right)_{f}$ predicted using Kondner's hyperbolic relationships at trial strains of $13,14,15,16$ and $17 \%$ along with the experimentally obtained values from which the finite failure strain can be considered to be equal to $15 \%$. This value of finite failure strain is in a good agreement with the value suggested by Nambiar et al. [5]. Also shown in Table (1) are the percentage agreements between the predicted and experimental values for each of the trial strain used.

Table 1. Predicted \& experimental values of deviator stress of the MST test at confining pressure $=700 \mathrm{kPa}$

\begin{tabular}{|c|c|c|c|c|c|c|}
\hline Parameter & \multicolumn{5}{|c|}{ Predicted values } & Experimental values \\
\hline $\boldsymbol{\varepsilon}_{\mathbf{a}}(\boldsymbol{\%})$ & 13 & 14 & 15 & 16 & 17 & - \\
\hline$\left(\boldsymbol{\sigma}_{\mathbf{1}}-\boldsymbol{\sigma}_{\mathbf{3}}\right)_{\boldsymbol{f}}(\mathrm{kPa})$ & 331.6 & 332.5 & 333.3 & 334.0 & 334.6 & 333 \\
\hline Agreement $\mathbf{( \% )}$ & 99.6 & 99.8 & 99.9 & 99.7 & 99.5 & - \\
\hline
\end{tabular}

The data obtained from the MST test for the near failure 3\% strain are linearized to obtain Kondner's hyperbolic constants and the results are shown in Fig. 5. Using the obtained empirical constants and applying the finite failure strain in Eqn. (1), the deviator stresses at failure are predicted and used to draw the Mohr-Coulomb failure envelope shown in Fig. 6, from which the shear strength parameters are found to be as follows: cohesion, $c^{\prime}=23 \mathrm{kPa}$ and friction angle, $\phi^{\prime}=30^{\circ}$. These results are in excellent agreement with those obtained from the CTC tests. This indicates that use of MST testing and proposed procedure has a good potential in obtaining reliable shear strength parameters of 
soil. The proposed procedure examined in this paper to rectify the MST results ensures accuracy without the need for an additional conventional triaxial experiment and thus reduces the financial costs and time associated with determining the shear strength parameters of soil.

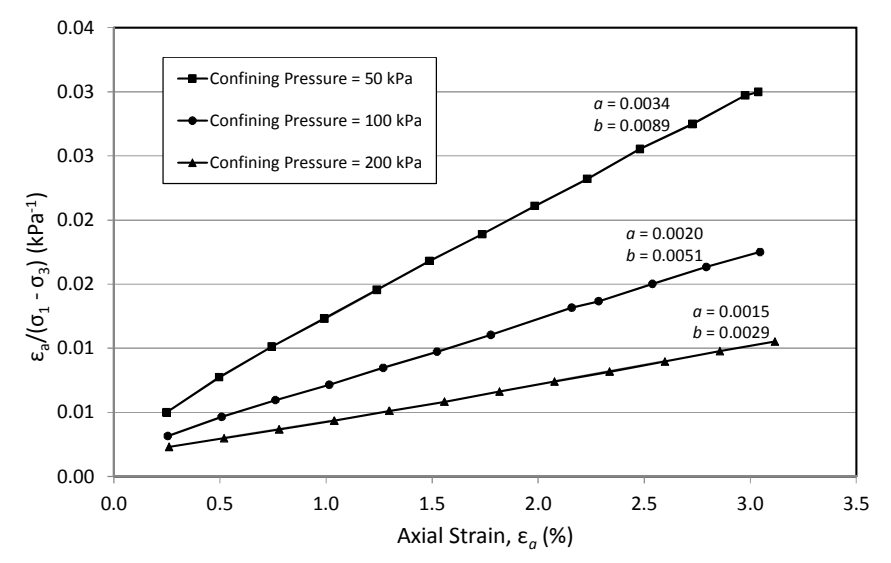

Fig. 5: Stress-strain hyperbolic linearization of the
MST test

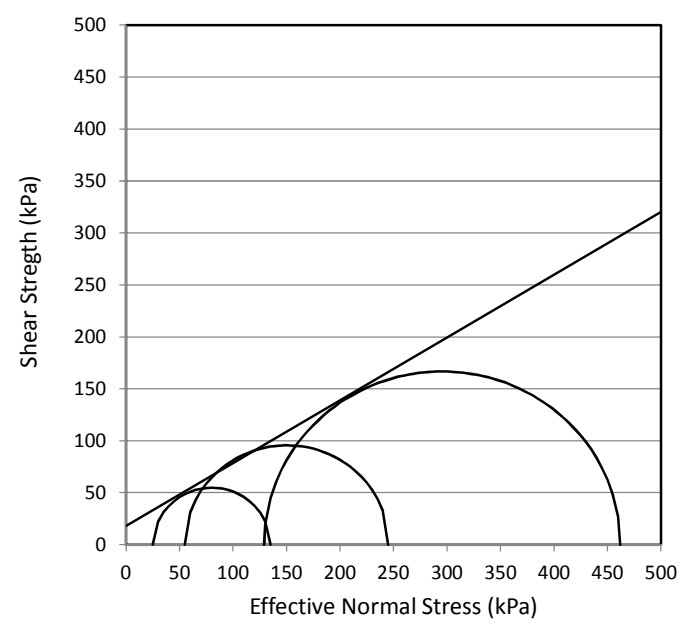

Fig. 6: Mohr-Coulomb failure envelope of the MST test

\section{Conclusions}

The results of this study have shown that multi-stage triaxial compression test can be used successfully as an economical alternative to traditional triaxial compression tests in obtaining reliable soil shear strength parameters. The main advantage of multi-stage triaxial test over traditional triaxial test is that multi-stage test can give reliable shear strength parameters without increasing the associated laboratory costs. However, reliable prediction of failure stresses from the multi-stage test results requires accurate determination of the finite failure strain at which failure stresses at each stage of the multi-stage loading should be calculated. This requires an additional triaxial test to be conducted on an individual soil specimen. This study aimed to present a new method for multi-stage triaxial test that can be used to obtain accurate shear strength parameters without the need for carrying out an additional triaxial test. The proposed method has found to give shear strength parameters that are comparable to those obtained from the traditional triaxial tests for a $c$-phi soil.

\section{References}

[1] E. De Beer, The cell test: Geotechnique Vol. 2 (1950), p. 162-172.

[2] T.C. Kenney and G.H. Watson, Multi-stage triaxial for determining c' and phi' of saturated soils, in: Proceedings of the 5th International Conference on Soil Mechanics and Foundation Engineering, Paris, France (1961), p. 191-195.

[3] A.M. Sridharan and S.N. Rao, New Approach to multistage triaxial test Journal of Soil Mechanics and Foundations Division Vol. 98 (1972), p. 1279-1286.

[4] R.L. Kondner, Hyperbolic stress-strain response: cohesive soils: Journal of Soil Mechanics and Foundations Division Vol. 89 (1963), p. 115-143.

[5] M.R. Nambiar, G.V. Rao and S.K. Gulhati, Multistage triaxial testing: A rational procedure: Strength Testing of Marine Sediments: Laboratory and In-Situ Measurements Vol. 883 (1985), p. 274-293. 